\title{
Diretivas antecipadas de vontade: desafios legais e educacionais na visão de enfermeiros
}

\author{
Isabela Saioron ${ }^{1}$, Flávia Regina Souza Ramos ${ }^{2}$, Felipa Rafaela Amadigi ${ }^{3}$, Paola da Silva Diaz ${ }^{4}$
}

\author{
${ }^{1}$ Enfermeira, Mestre em Enfermagem. \\ Discente do Programa de Pós-Graduação em \\ Enfermagem da Universidade Federal de \\ Santa Catarina, nível Doutorado. \\ Florianópolis, SC, Brasil. E-mail: \\ isabelasaioron@gmail.com. \\ ${ }^{2}$ Enfermeira, Doutora em Enfermagem. \\ Professora Titular da Universidade Federal de \\ Santa Catarina. Florianópolis, SC, Brasil. E- \\ mail: flavia.ramos@ufsc.br. \\ ${ }^{3}$ Enfermeira, Doutora em Enfermagem. \\ Professora Adjunta da Universidade Federal \\ de Santa Catarina. Florianópolis, SC, Brasil. E- \\ mail: felipaamadigi@yahoo.com.br. \\ ${ }^{4}$ Enfermeira, Mestre em Enfermagem. \\ Discente do Programa de Pós-Graduação em \\ Enfermagem da Universidade Federal de \\ Santa Catarina, nível Doutorado. \\ Florianópolis, SC, Brasil. E-mail: \\ enfpaoladiaz@gmail.com.
}

Recebido: 05/10/2016.

Aceito: 11/09/2017.

Publicado: 15/12/2017.

\section{Como citar esse artigo:}

Saioron I, Ramos FRS, Amadigi FR, Diaz PS. Diretivas antecipadas de vontade: desafios legais e educacionais na visão de enfermeiros. Rev. Eletr. Enf. [Internet]. 2017 [acesso em: ____;19:a44. Disponível em: http://dx.doi.org/10.5216/ree.v19.43587.

\section{RESUMO}

As Diretivas Antecipadas de Vontade (DAV) são um registro documental no qual o indivíduo descreve os procedimentos que gostaria ou não de ser submetido. Objetivou-se neste artigo discutir os desafios emergentes com o uso das DAV em termos éticos-legais e educacionais na visão de enfermeiros. Estudo qualitativo exploratório realizado mediante entrevistas semiestruturadas com 19 enfermeiros de Terapia Intensiva e Clínica Médica de um Hospital Universitário. A análise dos dados conduziu-se segundo a técnica de Análise Textual Discursiva. Emergiram duas grandes categorias de desafios associados às DAV: Desafios legais à sua adoção no Brasil e Desafios educacionais e de conhecimento relacionados à adoção das DAV; além de outros resultados aqui também explicitados. O tabu referente à morte, a carência de respaldo legal e de capacitações profissionais acerca da terminalidade e autonomia do enfermo surgem como desafios à divulgação e utilização das DAV na realidade estudada.

Descritores: Diretivas Antecipadas; Enfermagem; Educação em Enfermagem; Responsabilidade Legal.

\section{INTRODUÇÃO}

Na década de 60, nos Estados Unidos da América, o advogado Luis Kutner propôs a proteção do direito individual da morte mediante a adoção do que chamou de living will (testamento vital) por acreditar no potencial desse documento para solucionar conflitos entre médicos e familiares quanto aos cuidados a serem prestados a um enfermo em terminalidade ${ }^{(1-3)}$.

O living will foi o precursor do instrumento atualmente conhecido como Diretivas Antecipadas de Vontade (DAV). As DAV são um registro documental no qual o indivíduo manifesta quais os procedimentos que gostaria ou não de ser submetido em determinadas circunstâncias, expondo seus posicionamentos sobre 
procedimentos futuros ${ }^{(1,4)}$. No presente citado documento o autor consegue deixar explícito seus desejos caso se encontre incapacitado de manifestá-los verbalmente por futura condição de doença, exercitando assim sua autonomia ${ }^{(5)}$.

Embora o seu uso seja regulamentado no Brasil pela Resolução 1.995/2012 do Conselho Federal de Medicina (CFM), desde o ano de 2012, as DAV continuam pouco conhecidas pelos profissionais da saúde na atualidade. Tal desconhecimento pode gerar incertezas entre esses trabalhadores caso se deparem com essa documentação em algum momento do cotidiano laboral; o que, inclusive, pode entrar em conflito com o saber técnico institucionalizado ${ }^{(4,6)}$.

A pouca familiaridade com as DAV pode ser, em parte, reflexo da postura paternalista, a qual comumente exclui o enfermo da participação das decisões referentes aos tratamentos a serem utilizados ${ }^{(5)}$. Outro aspecto marcante seria a dificuldade dos profissionais da saúde em lidar com o óbito dos enfermos sob seus cuidados, uma vez que a formação acadêmica é ainda influenciada pelas práticas curativistas, pelo despreparo para lidar com a terminalidade e pela percepção da morte como fracasso(6).

Além do pressuposto, cabe salientar que, apesar da regulamentação da Resolução 1.995/2012 do CFM, as DAV ainda não possuem respaldo legal no Brasil ${ }^{(4,7)}$, uma vez que as resoluções ditadas pelo CFM orientam apenas as condutas médicas diante das vontades expressas pelo enfermo sob seus cuidados. Outra fragilidade a se considerar, são as lacunas existentes na literatura nacional sobre a aplicação das DAV e os desafios que podem surgir com sua utilização, especialmente no cotidiano laboral dos enfermeiros.

Reconhecendo a complexidade da temática, questionou-se: como os enfermeiros percebem os desafios referentes às DAV, caso sejam aplicadas ao seu fazer profissional?

Assim, objetivou-se discutir desafios emergentes com o uso das DAV em termos éticos-legais e educacionais na visão de enfermeiros. Embora tais desafios possam se apresentar em diferentes contextos de trabalho, foi eleito um cenário assistencial onde situações de terminalidade são comuns, no caso, Unidades de Terapia Intensiva e Clínicas Médicas.

\section{MÉTODOS}

O estudo delineou-se como exploratório com abordagem qualitativa, tendo como instrumento de coleta de dados a entrevista semiestruturada com 19 enfermeiros, incluindo residentes, atuantes nas unidades de Terapia Intensiva e Clínica Médica I e II de um Hospital Universitário do sul do país. A escolha destas unidades hospitalares se deu por serem unidades que possuem maior contato com situações de gravidade e/ou terminalidade, nas quais as DAV podem ser mais utilizadas. A opção por participantes enfermeiros deu-se pela importância de explorar a temática especificamente entre estes profissionais porque se encontram mais próximos do enfermo e de seus acompanhantes, podendo enfrentar maior desgaste emocional devido ao contato direto com o sofrimento do outro ${ }^{(8)}$, além da precariedade de estudos sobre esta temática com esses profissionais.

O estudo foi submetido e aprovado pelo Comitê de Ética em Pesquisa com Seres Humanos da 
Universidade Federal de Santa Catarina (Parecer no 1.353.986), sendo respeitados todos os aspectos éticos previstos na Resolução 466/2012 do Conselho Nacional de Saúde ${ }^{(9)}$.

O convite para participação na pesquisa ocorreu utilizando-se a técnica snowball, onde os participantes iniciais indicaram outros participantes, sucessivamente, até que foi evidenciada a saturação qualitativa dos dados ${ }^{(10)}$. Recusaram-se a participar da pesquisa três enfermeiros convidados. As entrevistas ocorreram após a leitura e concordância com o Termo de Consentimento Livre e Esclarecido pelos participantes

A coleta de dados ocorreu de janeiro a março do ano de 2016, sendo as entrevistas realizadas no local de trabalho dos participantes, áudio-gravadas e posteriormente transcritas na íntegra. Para garantir o anonimato dos entrevistados, as falas foram nomeadas pela letra " $\mathrm{P}$ " (profissional), seguida do número indicativo da ordem das entrevistas (P01, P02, e assim, sucessivamente).

Para a análise utilizou-se o método de Análise Textual Discursiva (ATD) composta por quatro focos: desmontagem dos textos ou processo de unitarização, que enfatiza os principais elementos que os constituem, após minuciosas leituras; estabelecimento de relações, que consiste na elaboração de categorias; captação do novo emergente no qual se explicita a compreensão obtida e, finalmente, o processo auto-organizado, que busca estabelecer interlocuções teóricas e novas compreensões acerca do fenômeno estudado até então(11).

As etapas da ATD foram amparadas pelo uso do software Atlas ti, uma vez que os processos de fragmentação e posterior unitarização dos dados são compatíveis com as ferramentas oferecidas por este recurso. Assim, os dados foram classificados e agrupados por semelhança, com eleição de categorias analíticas que promovessem a captação de um novo emergente, ou seja, compreensão obtida através da interpretação da temática e da elaboração de um metatexto, de possíveis críticas e da validação dos dados, interpretando os significados e relacionando-os ao corpus original.

\section{RESULTADOS}

A maioria dos enfermeiros entrevistados era do sexo feminino, possuía experiência profissional prévia e mais de uma pós-graduação completa. A maioria também referiu desconhecer as DAV, assim como sua utilização no Brasil, sendo necessária uma explicação prévia sobre o tema.

A partir da fala dos enfermeiros foi possível agrupar os desafios representados pelas DAV ao fazer profissional em duas grandes categorias, conforme Quadro 1 e 2: Desafios legais à adoção das DAV no Brasil e Desafios educacionais e de conhecimento relacionados à adoção das DAV.

Como se pode perceber, o desconhecimento das DAV e a falta de amparo legal atrelada à abordagem deficitária da terminalidade durante a formação acadêmica, tradicionalmente voltada ao curativismo e tecnicismo, expõem uma realidade complexa e desafiadora vivida pelos enfermeiros que atuam com pacientes em processo de morte/morrer. Esta situação parece gerar insegurança nesses profissionais, além de limitar a função das DAV à mera informação adicional, sem grande relevância para direcionar as condutas 
terapêuticas.

Quadro 1: Síntese de achados da categoria 1.

Desafios legais à adoção das DAV no Brasil

\begin{tabular}{|c|c|}
\hline \multicolumn{2}{|r|}{ Desafios legais à adoção das DAV no Brasil } \\
\hline \multirow{4}{*}{$\begin{array}{c}\text { Embora existam } \\
\text { manifestações favoráveis } \\
\text { quanto a importância de } \\
\text { saber a vontade do enfermo, } \\
\text { os profissionais explicitam } \\
\text { que sentem a necessidade de } \\
\text { se resguardarem de possíveis } \\
\text { problemas judiciais. As falas } \\
\text { dos entrevistados } \\
\text { demonstram insegurança em } \\
\text { seguir as vontades do } \\
\text { enfermo sem que haja uma } \\
\text { lei regulamentando as DAV. }\end{array}$} & $\begin{array}{c}\text { [...] Quando não tá na lei a gente fica um pouco receoso, 'estou fazendo o certo? É correto isso? } \\
\text { Vai de acordo com o juramento que eu fiz?' isso é um pouco complicado ainda. E estando na lei } \\
\text { seria mais respeitado, seria mais fácil de aceitar porque é legal. Não tendo esse respaldo a } \\
\text { gente pensa duas vezes, gera uma insegurança porque você não sabe o que pode acontecer } \\
\text { depois (P01). }\end{array}$ \\
\hline & $\begin{array}{l}\text { [...] você tem ali a opinião, o desejo do paciente escrito, acho que isso é interessante até certo } \\
\text { ponto. Isso realmente tem certa influencia, mas no final realmente, numa situação de } \\
\text { terminalidade, não tendo respaldo legal, infelizmente nós teríamos que tomar as condutas } \\
\text { legais e não apenas apoiado na opinião dele. [...] para fins de defesa profissional pra equipe } \\
\text { como um todo e para o próprio hospital. Se tivesse respaldo, a situação seria outra [...] (P05). }\end{array}$ \\
\hline & $\begin{array}{c}\text { [...] até que se tenha força de lei, talvez a gente fique só no guia, porque tudo bem, você pode } \\
\text { até ter uma noção do que o paciente quer ou não quer, numa situação que você tem que decidir } \\
\text { de urgência, talvez aquilo ali seja o fator decisivo, mas tem a questão legal. Aí o profissional, se } \\
\text { for uma questão que ele vê que tem que intervir, ele vai intervir temendo que depois tenha uma } \\
\text { questão judicial (PO7). }\end{array}$ \\
\hline & $\begin{array}{c}\text { Eu acho complicado não ter uma lei, porque onde a gente vive tudo é lei, então se a família } \\
\text { quiser levar pra justiça que o paciente não foi assistido, foi negligenciado, a equipe pode } \\
\text { responder por isso porque não existe uma lei, então, na minha percepção seria bem difícil [...] } \\
\text { Para o profissional não dá segurança, o profissional fica meio inseguro de agir como o paciente } \\
\text { quer (P11). }\end{array}$ \\
\hline
\end{tabular}

Quadro 2: Síntese de achados da categoria 2.

\begin{tabular}{|c|c|}
\hline \multicolumn{2}{|r|}{ Desafios educacionais e de conhecimento relacionados à adoção das DAV } \\
\hline \multirow{5}{*}{$\begin{array}{l}\text { Apesar de reconhecerem que } \\
\text { a lei seria de grande } \\
\text { importância, alguns } \\
\text { esclarecem que isoladamente } \\
\text { ela seria insuficiente, } \\
\text { havendo a necessidade de } \\
\text { ampliar a divulgação das } \\
\text { DAV. No contexto } \\
\text { profissional seria necessário } \\
\text { ampliar as discussões sobre } \\
\text { ética e terminalidade nas } \\
\text { ações de educação } \\
\text { permanente, bem como } \\
\text { aprofundar estas discussões } \\
\text { durante a formação, } \\
\text { combatendo a formação } \\
\text { tecnicista e paternalista. }\end{array}$} & $\begin{array}{c}\text { Acho que para o profissional acatar o melhor caminho seriam as especializações, acho que seria } \\
\text { algo mais instrutivo [...] por exemplo, o Ministério da Saúde faz as suas cartilhas, seus manuais, } \\
\text { é algo que a gente lê, é confiável, a gente vai se atualizando todo ano, então acho que a partir } \\
\text { do momento que a gente tiver maiores estudos, e que seja divulgado e discutido com } \\
\text { profissionais, de repente é até mais válido para a gente digerir todo esse processo, inserir na } \\
\text { nossa cultura de trabalho do que uma lei que venha de cima pra baixo, que seja pouco } \\
\text { discutida, que seja normativa [...] eu vejo que a gente tem vários caminhos para se chegar a } \\
\text { esse ponto ideal que não só a lei (P17). }\end{array}$ \\
\hline & $\begin{array}{l}\text { Eu tive na graduação ao todo uma aula sobre morte, uma } \\
\text { na residência mesmo [...] Quem está o dia todo na unidad } \\
\text { lidar com isso [...] Foca muito no procedimento e a enferm }\end{array}$ \\
\hline & $\begin{array}{c}\text { Querendo ou não a gente ainda é formado para reestabelecer a saúde das pessoas. [...] } \\
\text { Respeitar a decisão da pessoa é muito difícil. Não tem um ser humano dentro dessa clínica que } \\
\text { respeite concordando, a gente respeita discordando. É muito sinistro você viver com essa } \\
\text { ambiguidade [...] A gente aborda a questão da terminalidade muito precariamente [...] quando } \\
\text { chegam pessoas novas e percebem a quantidade de pessoas que morrem elas ficam } \\
\text { horrorizadas. Porque não é ensinado como uma coisa natural. Por incrivel que pareça morrer é } \\
\text { natural (P15). }\end{array}$ \\
\hline & $\begin{array}{l}\text { A gente tem uma formação muito biomédica, então a gente está acostumado a intervir muito } \\
\text { no paciente, checar sinal vital, fazer medidas curativas, medidas heroicas. E um paciente que } \\
\text { você vai cuidar para conforto, que você não vai atuar muito em relação a doença dele, mas sim } \\
\text { só a qualidade de vida, a gente ainda encontra muitas barreiras entre os profissionais (P18). }\end{array}$ \\
\hline & $\begin{array}{c}\text { [...] Eu agora estou fazendo pós graduação em transplante e foi a primeira vez que eu tive } \\
\text { conhecimento realmente de como abordar o familiar naquele processo de morte [...] tinha que } \\
\text { saber como se aborda, como os familiares se comportam, o que é o luto, tentar entender que } \\
\text { determinados comportamentos são esperados (P19). }\end{array}$ \\
\hline
\end{tabular}

Como se pode perceber, o desconhecimento das DAV e a falta de amparo legal atrelada à abordagem 
deficitária da terminalidade durante a formação acadêmica, tradicionalmente voltada ao curativismo e tecnicismo, expõem uma realidade complexa e desafiadora vivida pelos enfermeiros que atuam com pacientes em processo de morte/morrer. Esta situação parece gerar insegurança nesses profissionais, além de limitar a função das DAV à mera informação adicional, sem grande relevância para direcionar as condutas terapêuticas.

\section{DISCUSSÃO}

As DAV possuem um grande entrave para sua aplicação: são pouco conhecidas pelos enfermeiros e demais profissionais da saúde, o que destaca a importância de ampliar as discussões sobre as mesmas ${ }^{(12)}$. Os desafios que vieram à tona em parte representam algo novo no contexto do cuidado no Brasil ${ }^{(13)}$, mas também remetem à antigas limitações, em torno da cultura ocidental contemporânea que coloca a vida como valor absoluto ${ }^{(5)}$. Também é reconhecido um relativo desinteresse da sociedade quanto a terminalidade humana, o que acaba reforçando a visão da morte como fracasso ou sinônimo de indignidade por parte de profissionais ${ }^{(14)}$.

Após serem esclarecidos sobre o conceito das DAV, sua aplicação e atual situação no Brasil, os participantes manifestaram significativa insegurança pelo fato de não haver uma legislação, além de sentirem-se frente a um dilema ético quando analisam a adoção das DAV à luz do Código de Ética dos Profissionais de Enfermagem.

No ano de 2009, houve uma tentativa de regulamentar a temática no Brasil, com a apresentação do projeto de lei no 524/2009. Contudo, o mesmo foi arquivado por encerramento de mandato legislativo, no ano de $2014^{(15)}$, de modo que a Resolução no 1.995/2012 do CFM permanece o único documento que dispõe sobre as DAV no país ${ }^{(4)}$.

A dificuldade de se elaborar leis capazes de contemplar situações que envolvam a autonomia na terminalidade de modo claro não é uma realidade restrita ao Brasil. Portugal e Espanha apresentam dificuldades similares ainda hoje, apesar de já terem regulamentação das DAV em lei ${ }^{(1-2)}$. Esse contexto turbulento se explica pela nossa constituição cultural, que influencia diversos setores da sociedade, inclusive o legislativo, que possui o objetivo primário de proteger a vida, dificultando a elaboração de leis que favoreçam o protagonismo dos indivíduos diante do processo de morrer, além do risco de surgirem leis ambíguas, confusas, que dêem margem a diversas interpretações na tentativa de favorecer esse protagonismo. Assim, não é rara a dificuldade em articular o binômio vida-liberdade e estabelecer quando um valor deve se submeter ao outro, especialmente quando o Estado tende a uma postura paternalista ${ }^{(16)}$.

Dessa forma, lidar com enfermos autores de DAV que tenham possibilidades terapêuticas é particularmente desafiador, pois o senso de responsabilidade e o envolvimento emocional com a clientela podem gerar conflitos e até sofrimento ante o pedido de limitação de investimentos solicitado por esses autores $^{(10-21)}$.

Embora os resultados desse estudo tenham apontado que os enfermeiros se sentem inseguros com a 
ausência de leis regulamentando as DAV no Brasil, a literatura atual traz que a elaboração de leis não ameniza os desafios referentes a essa documentação, em virtude da dificuldade de se favorecer a autogestão do enfermo no momento do adoecimento e morte ${ }^{(16)}$.

A formação profissional, seja durante a graduação, nas atividades de educação permanente ou na pós graduação, podem auxiliar os enfermeiros no enfrentamento da terminalidade. Assim sendo, o desenvolvimento profissional deve prosseguir de modo permanente e independente à elaboração de leis e resoluções, de modo a buscar soluções viáveis aos desafios oriundos das DAV. Tanto quanto o respaldo legal, o conhecimento é base imprescindível para a atuação segura por parte dos profissionais diante de problemáticas. Neste mesmo sentido, diversos estudos revelam a necessidade de uma melhor abordagem sobre a autonomia e a terminalidade desde a formação acadêmica. O forte apelo curativista e técnico desta formação, além do insuficiente preparo para enfrentar os limites da própria intervenção, dificulta a aceitação da morte e produz nos profissionais da saúde sentimentos de frustração ${ }^{(6-8,14,17-19)}$.

Apesar de se reconhecer que a terminalidade é uma temática pouco abordada na formação acadêmica dos profissionais da saúde em geral, reconhece-se que os enfermeiros compõem uma das categorias profissionais com atuação mais próxima do enfermo e de seus acompanhantes. Em virtude disso, se desgastam mais emocionalmente em face da proximidade e do contato com o sofrimento alheio ${ }^{(8)}$. Pela complexidade do tema e pelo papel dos enfermeiros nas equipes de saúde, talvez seja uma das categorias que mais tem se sensibilizado para o interesse de mudanças curriculares que aprofundem o debate ético envolvendo a autonomia, as DAV e suas vertentes, além de temas que envolvam a terminalidade e a relação entre cultura, saúde, doença e morte.

\section{CONCLUSÃO}

A partir das falas dos entrevistados foi possível identificar os desafios que os enfermeiros projetam com relação à aplicabilidade das DAV para suas práticas futuras. Percebeu-se que as DAV são pouco conhecidas pelos enfermeiros, remetendo essa escassa divulgação a um reflexo da realidade que afeta não apenas esses profissionais e na qual a morte ainda é um tabu, a autonomia dos enfermos possui pouco estímulo e o tecnicismo predomina nas atividades laborais.

Dentre os desafios identificados, o medo de sofrer processos judiciais em virtude da ausência de uma legislação voltada para as DAV foi expressivo nas falas dos participantes. Nota-se aqui a importância dos enfermeiros se sentirem seguros para que os avanços referentes à relação profissional da saúde-enfermo possam se consolidar.

Uma maneira de favorecer a segurança desses profissionais seria a informação. $\mathrm{O}$ fato dos profissionais descreverem a necessidade de capacitações e de ampliação nas discussões sobre a terminalidade sugere ser primordial uma abordagem mais aprofundada do tema desde a formação acadêmica. A formação ética e baseada em valores é necessária para sustentar uma atuação mais segura, para respeitar e promover o exercício da autonomia das pessoas que necessitam de cuidados e também, para estimular mudanças 
legislativas.

\section{REFERÊNCIAS}

1. Alves CA. Diretivas antecipadas de vontade e testamento vital: uma interface nacional e internacional. In: Pessini $L$, Bertachini L, Barchifontaine CP, editores. Bioética, cuidado e humanização. São Paulo: Loyola; 2014. p. $137-57$.

2. Dadalto L. Reflexos jurídicos da Resolução CFM 1.995/12. Rev Bioética [Internet]. 2013 [acesso em: 11 dez. 2017];21(1):106-12. Disponível em: http://doi.org/10.1590/S1983-80422013000100012.

3. Dadalto L, Tupinambás U, Greco DB. Diretivas antecipadas de vontade: um modelo brasileiro. Rev Bioética [Internet]. 2013 [acesso em: 11 dez. 2017];21(3):463-76. Disponível em: http://doi.org/10.1590/S198380422013000300011.

4. Conselho Federal de Medicina. Resolução № 1.995, de 09 de agosto de 2012 (BR) [Internet]. Dispõe sobre as diretivas antecipadas de vontade dos pacientes. Diário Oficial da União. 31 ago. 2012 [acesso em: 11 dez. 2017], p. 269-70. Disponível em:

http://pesquisa.in.gov.br/imprensa/jsp/visualiza/index.jsp?data=31/08/2012\&jornal=1\&pagina=269\&totalArquivos=2 72.

5. Bermejo JC Belda RM, editores. Testamento Vital: diálogo sobre a vida, a morte e a liberdade. São Paulo: Loyola; 2015. 99 p.

6. Santana JCB, Santos AV dos, Silva BR da, Oliveira DC dos A, Caminha EM, Peres FS, et al. Docentes de enfermagem e terminalidade em condições dignas. Rev Bioética [Internet]. 2013 [acesso em: 11 dez. 2017];21(2):298-307. Disponível em: http://doi.org/10.1590/S1983-80422013000200013.

7. Kovács MJ. A caminho da morte com dignidade no século XXI. Rev Bioética [Internet]. 2014 [acesso em: 11 dez. 2017];22(1):94-104. Disponível em: http://doi.org/10.1590/S1983-80422014000100011.

8. Hermes HR, Lamarca ICA. Cuidados paliativos: uma abordagem a partir das categorias profissionais de saúde. Cien Saude Colet [Internet]. 2013 [acesso em: 11 dez. 2017];18(9):2577-88. Disponível em: http://doi.org/10.1590/S141381232013000900012.

9. Resolução No 466 do Conselho Nacional de Saúde, de 12 de dezembro de 2012 (BR) [Internet]. Aprova as diretrizes e normas regulamentadoras de pesquisas envolvendo seres humanos. Diário Oficial da União. 12 dez. 2012 [acesso em: 11 dez. 2017]. Disponível em: http://bvsms.saude.gov.br/bvs/saudelegis/cns/2013/res0466_12_12_2012.html. 10. Baldin N, Munhoz EMB. Snowball (Bola de Neve): uma técnica metodológica para pesquisa em educação ambiental comunitária. In: Anais do 10 Congresso Nacional de Educação [CD-ROM], 2011, Curitiba, Brasil.

11. Moraes R, Galiazzi, M. Análise textual discursiva. ljuí: Unijuí; 2011.

12. Chehuen Neto JA, Ferreira RE, Silva NCS, Delgado AHA, Tabet CG, Almeida GG, et al. Testamento vital: o que pensam profissionais de saúde? Rev Bioética [Internet]. 2015 [acesso em: 11 dez. 2017];23(3):572-82. Disponível em: http://doi.org/10.1590/1983-80422015233094.

13. Cassol PB, Quintana AM, Velho MTAC. Diretiva antecipada de vontade: percepção de uma equipe de enfermagem da hemato-oncologia. J Nurs Health [Internet]. 2015 [acesso em: 11 dez. 2017];5(1):4-13. Disponível em:

https://periodicos.ufpel.edu.br/ojs2/index.php/enfermagem/article/view/5497.

14. Saioron I. Processo de ortotanásia em unidade de terapia intensiva: percepção dos profissionais de saúde [monografia]. Rio Grande: FURG; 2014.

15. Pona EW, Amaral ACCZM. Os (des) caminhos do testamento vital no Brasil: entre a legislação nascente e a regulamentação pelo Conselho Federal de Medicina. Revista da Sociedade Brasileira de Bioética [Internet]. 2013 [acesso em: 11 dez. 2017];9(supl.):240-1. Disponível em: https://rbbioetica.files.wordpress.com/2014/11/anais-do-xcongresso-brasileiro-de-bioc3a9tica-20131.pdf.

16. Gracia D. Ética y toma de decisiones en el final de la vida. In: Porto D, Schlemper B, Martins GZ, Cunha T, Hellmenn F, editores. Bioética: saúde, pesquisa, educação. Conselho Federal de Medicina \& Sociedade brasileira de Bioética; 2014. p. 223-24.

17. Felix ZC, Costa SFG, Alves AMPM, Andrade CG, Duarte MCS, Brito FM. Eutanásia, distanásia e ortotanásia: revisão integrativa da literatura. Cien Saude Colet [Internet]. 2013 [acesso em: 11 dez. 2017];18(9):2733-46. Disponível em: http://doi.org/10.1590/S1413-81232013000900029. 
18. Sanchez y Sanches KM, Seidl EMF. Ortotanásia: uma decisão frente à terminalidade. Interface - Comun Saúde, Educ [Internet]. 2013 [acesso em: 11 dez. 2017];17(44):23-34. Disponível em: http://doi.org/10.1590/S141432832013000100003.

19. Junges JR, Cremonese C, Oliveira EA, Souza LL, Backes V. Reflexões legais e éticas sobre o final da vida: uma discussão sobre a ortotanásia. Rev Bioética [Internet]. 2010 [acesso em: 11 dez. 2017];18(2):275-88. Disponível em: http://revistabioetica.cfm.org.br/index.php/revista_bioetica/article/viewArticle/564.

20. Lopera Betancur MA. Nursing care of patients during the dying process: a painful professional and human function. Invest Educ Enferm [Internet]. 2015 [acesso em: 11 dez. 2017];33(2):297-304. Disponível em: http://doi.org/10.17533/udea.iee.v33n2a12.

21. Tschirhart EC, Du Q, Kelley AS. Factors influencing the use of intensive procedures at the end of life. J Am Geriatr Soc [Internet]. 2014 [acesso em: 11 dez. 2017];62(11):2088-94. Disponível em: http://doi.org/10.1111/jgs.13104. 